\title{
Late Adolescent Identity Development: Narrative Meaning Making and Memory Telling
}

\author{
Kate C. McLean \\ University of Toronto
}

\begin{abstract}
Personally important autobiographical memories are the smallest unit of the life story, which begins to emerge in adolescence. This study examined 2 features of self-defining memories in late adolescence, the meaning made of the memories to garner an understanding of the narrative construction of identity as a life story and how those memories were told with an emphasis on the functions for telling and audiences to understand the social component of narrative identity development. For late adolescents $(N=185)$, meaning was infrequently reported for the entertainment function in comparison with the self-explanation function. At later ages, adolescents' audiences were more likely to be peers, and at earlier ages, adolescents' audiences were more likely to be parents. Discussion focuses on the individual and social levels of identity construction that are apparent in personally important autobiographical memory narratives.
\end{abstract}

Keywords: narrative, identity, adolescence, autobiographical memory, memory telling

Identity development is one of the major psychosocial tasks of late adolescence and has important implications for healthy psychological development throughout the life course (Erikson, 1968). McAdams $(1993,2001)$ proposed that identity is a life story, which begins to be formed in late adolescence (see also Habermas \& Bluck, 2000). One of the guiding principles of the life story theory of identity is that life stories serve to make sense of one's past, present, and anticipated future and are partly constructed by making meaning of past experience. One way that the narrative construction of meaning making occurs is when memories are told to others (Pasupathi, 2001; Thorne, 2000; Thorne, McLean, \& Lawrence, 2004), and a recent push to situate identity in the contexts in which it is formed calls for examining specific contexts as well as individual intentions in story making (Thorne, 2004). Therefore, this study examined late adolescents' selfdefining memories and the meaning reported for different functions of memory telling as well as the significance of parent and peer audiences for these stories.

Portions of this article were presented at the Biennial Meeting of the Society for Research on Adolescence, Baltimore, Maryland, March 2004. Portions of this article are based on a doctoral dissertation submitted by Kate C. McLean in partial fulfillment of the PhD requirements of the University of California, Santa Cruz.

I thank those who read drafts of this article and provided thoughtful commentary and support for this project, particularly my graduate advisor, Avril Thorne, as well as Margarita Azmitia, Mara Mather, and Lewis Jones. I also thank my research assistants, Danny Ambrose, Stefan Esposito, Brooke Hollister, Natasha Molony, and Yasmin Verdugo, for their careful work collecting, coding, and thinking about these data.

Correspondence concerning this article should be addressed to Kate C. McLean, Department of Psychology, University of Toronto, 2259 Mississauga Road North, Room 2037B, Mississauga, Ontario L5L 1C6, Canada. E-mail: kmclean@utm.utoronto.ca

\section{Meaning Making and Identity Development}

Meaning making is a kind of causal coherence used to integrate experiences, which emerges as late adolescents begin to think about constructing their life stories in order to explain how a past event led to or influenced another event or aspect of the self (Habermas \& Bluck, 2000). Although the construction of identity and the meaning of past experiences are lifelong processes (Erikson, 1968; Harter, 1999; Kroger, 2000; McAdams, 1993), there are different points in the life span when identity work and meaning making are heightened. The life story begins to emerge in adolescence because of the onset of formal operations, physiological maturity, and often the demands for establishing oneself in the world through work, school, and family, demands that tend to allow for or even require meaning making (Grotevant, 1993; Habermas \& Bluck, 2000; McAdams, 2001). Further, during disruptive episodes, such as transitions, cognitive demands are higher to make sense of new experiences (Azmitia, 2002; Piaget, 1965; Surra \& Bohman, 1991). The participants in this study were late adolescents and were undergoing the major transition of beginning college. Meaning making may be paramount during the transition to college as adolescents must not only integrate their new surroundings but also communicate who they are in a new environment.

Like this study, prior research on meaning making with adolescents has used self-defining memories as the narrative unit of analysis because these memories are central to one's sense of self and become fodder for constructing the life story (Blagov \& Singer, 2004; McLean \& Thorne, 2003, in press; Thorne, 2000; Thorne \& McLean, 2002, 2003; Thorne et al., 2004). McLean and Thorne (2003) defined two specific kinds of meaning in late adolescent's self-defining memory narratives, lesson learning and gaining insight, which will also be examined in the present study (see also Blagov \& Singer, 2004; McCabe, Capron, \& Peterson, 1991; Pratt, Norris, Arnold, \& Filyer, 1999; Thorne et al., 2004). Lesson learning refers to learning a specific lesson from an event 
that could direct future behavior in similar situations (e.g., "I should not talk back to my mother"). Gaining insight refers to gleaning meaning from an event that applies to greater areas of life than a specific behavior; with insight, there is often some kind of transformation in the understanding of oneself or others (e.g., "I realized that I was an independent person").

This study explored meaning making and identity development by looking at a social context in which identity may be constructed: memory telling. First, whether meaning is more important to certain functions of memory telling was examined. Second, the differences in parent and peer audiences of self-defining memories were examined.

\section{Memory Telling}

Memory telling serves an important purpose in identity construction, particularly in adolescence (Thorne, 2000; see also Pasupathi, 2001). The recent focus on memory telling and identity is important because although prior research on narrative identity has appreciated the historical and cultural context of the rememberer, the process of life story construction is often presumed to be internal (e.g., McAdams, 1993). Further, research on the functions of autobiographical memory has distinguished between personal functions (e.g., reflecting on a past event in private to better understand oneself) and social functions (e.g., developing intimacy through sharing past events; Alea \& Bluck, 2003; Pillemer, 1992; Webster, 2003). However, this study takes the perspective that personal and social functions are inseparable in studying the social telling of personal self-defining memories (McLean \& Thorne, in press; Pasupathi, in press). The latter perspective is based on Nelson's (2003) suggestion that although memory can be viewed as an individual phenomenon, narrative, the manner in which memories are stored and communicated, is a social phenomenon (see also Bruner, 1990). This study takes an important step in understanding the development of narrative identity because it brings the social process of memory telling, which occurs frequently (e.g., Rimé, Mesquita, Philippot, \& Boca, 1991), squarely to the center of narrative identity development.

Specifically, this study examined an array of telling functions late adolescents reported and then focused on the two most common telling functions, entertainment and self-explanation. Memories told for self-explanation were expected to be reminiscent of the narratives studied in most research on narrative identity, which primarily examines how people draw meaning and resolution from difficult and challenging life events (e.g., King, 2001; McLean \& Thorne, 2003; Pals, 2005). Research on the events that people use to define themselves in their everyday lives is relatively sparse (McLean \& Thorne, in press; Pasupathi, in press), and memories told for entertainment were expected to fit in this realm. Importantly, in this study memories told for both self-explanation and entertainment were included as self-defining. The current study addresses the challenge to narrative researchers to understand how memories told for entertainment fit with current conceptions of narrative identity.

Telling functions were the focus of this study because they help to define memory-telling contexts as stories change based on the intent of the person telling them (e.g., Sanitioso, Kunda, \& Fong, 1990; Tversky \& Marsh, 2000). Certain features of narratives such as meaning may or may not be included in telling memories for different reasons. In one of the few existing studies on specific memory-telling functions (see Alea \& Bluck, 2003, for a review), self-explanation was the most common reason for telling memories in long-married couples (Pasupathi, Lucas, \& Coombs, 2002). Though the present sample is made up of late adolescents, selfexplanation was still expected to be a common function because social networks are expanding (Carstensen, 1995), affording many opportunities to explain oneself to others.

Most pertinent to the present study, a recent study of college students found that telling for self-related reasons versus entertainment was associated with reporting different narratives of recent past events (Pasupathi, 2005). Using a word count technique (Pennebaker \& Francis, 1999, Pasupathi (2005) found that insight words were more common in memories told to seek and transmit meaning than in memories told to entertain. Although Pasupathi's (2005) study used a linguistic and not a narrative analysis, her results indicate that the self and entertainment functions are associated with different narrative patterns.

The present study extended Pasupathi's (2005) work and is one of the first studies to take a narrative approach to memory-telling functions. In addition, rather than examine recent memories that were not clearly related to the self, the present study examined memories that were at least 1 year old and that were regarded as self-defining. The presence of explicit meaning in the memory narratives told for entertainment and self-explanation was examined, with the expectation that meaning would be more commonly reported in memories told for self-explanation than in memories told for entertainment.

It is important to note that it was not presumed that memories told for different functions embody the true narrative of those memories. Rather, it was presumed that narratives change depending on the motivations one has in different situations (e.g., Morling \& Epstein, 1997; see also Charles \& Pasupathi, 2003). Thus, this study aimed to look at how the contexts of telling for entertainment and telling for self-explanation revealed different aspects of persons and what those aspects can tell us about the diversity of narratives that are part of an individual's developing life stories.

\section{Parent and Peer Relationships}

An important factor in the phenomenon of late adolescent memory telling is the audiences with whom memories are shared. Because much prior research has shown parents and peers are central to adolescent identity development (e.g., Grotevant \& Cooper, 1985; Youniss \& Smollar, 1985), this study examined parent and peer audiences for telling functions as well as the ages of telling for two reasons.

First, prior research has shown that parental relationships tend to maintain their importance during adolescence and peer relationships tend to increase in importance and intimacy during adolescence (Grotevant \& Cooper, 1985; Sullivan, 1953; Youniss \& Smollar, 1985). Indeed, voluntary time spent with friends and later with romantic partners is greater in late adolescence than voluntary time spent with family (Furman, 1989; Larson \& Richards, 1991), and this time spent together becomes especially important as adolescents use friends and romantic partners for intimacy and support (Hunter \& Youniss, 1982; Reis, Lin, Bennett, \& Nezlek, 1993). It was expected that peers would increasingly make up 
telling audiences across adolescence, whereas parents would be more likely to be audiences for adolescents at younger ages.

Second, the transition to college is a particularly significant time for peer relationships. Establishing relationships is important for a successful adjustment to college (Shaver, Furman, \& Buhrmester, 1985), and self-telling may be one way to develop such networks. Because self-explanation is presumed to involve more intimate self-disclosure than entertainment, it was expected that peers would be more likely to hear stories told for self-explanation than for entertainment. Predictions were not made for family audiences and functions, as it was unclear whether decreases in time spent with family would be related to telling memories for different functions or telling less overall. These audiences were thus examined in an exploratory fashion.

Gender differences in telling rates and functions were also examined because prior research has found gender differences in self-disclosure, primarily in reference to the development of intimacy. Yet, results across different types of studies are not entirely clear. For example, a cross-sectional study found that adolescent girls experience an increase in intimacy with friends at a faster rate than adolescent boys (Sharabany, Gershoni, \& Hofman, 1981). A longitudinal study conducted by Rice and Mulkeen (1995) showed, however, that for boys intimacy increased and approached girls' levels by late adolescence (Rice \& Mulkeen, 1995). These results suggest the possibility that adolescent boys and girls act out intimacy in different ways (see Floyd, 1997). Indeed, Camarena, Sarigiana, and Peterson (1990) found that in early adolescence self-disclosure and shared experiences were predictors of intimacy for boys. As prior research is not conclusive and personal memory telling is a relatively recent area of study, gender was examined but in an exploratory fashion.

In sum, it was expected that memories told to explain the self would contain more meaning than would memories told to entertain. It was also expected that self-explanation memories would be more commonly shared with peers than would entertainment memories and that peers would become increasingly more common audiences across adolescence compared with parents, who would be more common audiences for adolescents at earlier ages. Because prior research is both limited and somewhat contradictory, examination of gender differences as well as the frequency and function of telling memories to family audiences was considered in an exploratory fashion.

\section{Method}

\section{Participants}

The sample consisted of 185 participants ( $42 \%$ male; $n=89$ ) collected from the psychology subject pool at a public university in northern California. Ages ranged from 16 to 27 years $(M=18.7$ years, $S D=1.2)$. Sixty-two percent of the participants described themselves as Caucasian $(n=115), 17 \%$ described themselves as Asian $(n=31), 6 \%$ described themselves as Latino $(n=11), 1 \%$ described themselves as African American $(n=2), 14 \%$ described themselves as mixed race $(n=14)$, and $4 \%$ of the participants were categorized as other $(n=7) .{ }^{1}$ Two percent of the participants did not report ethnicity $(n=5)$.

\section{Procedure}

A paper-based questionnaire that included the Self-Defining Memory Questionnaire was completed while participants were in a room alone.
Completion of the study took an average of 30-45 min. Other surveys were also administered but are not relevant to the present study.

The first page of the questionnaire (adapted from Singer \& Moffit, 1991-1992) elicited demographics (gender, age, ethnicity) and described features of a self-defining memory. A self-defining memory was described as a memory that is vivid, highly memorable, personally important, at least 1 year old, and the kind of memory that conveys powerfully how one has come to be the person one currently is (see Singer \& Moffitt, 1991-1992, p. 242). Participants were asked to report three self-defining memories.

The first section of each page included instructions for participants to title the memory and to report their age at the time of the event. Participants were then asked to describe the memory, including where they were, whom they were with, what happened, and the reaction of themselves and others who were involved in the event. The latter narrative was termed the event narrative.

The second section of each page asked participants to indicate with how many people they had shared the memory. Then, if they could recall a specific episode of having shared the memory, participants were asked to indicate with whom they had shared the memory, how long after the original event the memorable telling episode occurred, and to how many people it had been told. They were then asked to describe the telling episode, including what led them to tell the memory, the reaction of the listener, and their own reaction. The latter narrative was termed the telling narrative. An equal amount of space was provided to describe the event and telling narratives.

A supplement to the Self-Defining Memory Questionnaire was added for the purposes of this study in an effort to induce participants to elaborate memory telling and meaning making. After the event and telling narratives, participants (who reported telling the memory) were asked to describe if and how telling the memory helped them to better understand it. This narrative was termed the understanding narrative.

To target telling functions, participants chose from a list of five functions that were developed on the basis of pilot data and past research. Participants were asked to pick one function as the reason for why they had shared the memory. The functions comprised the following: to validate one's thoughts or feelings about the memory, to better understand the memory (meaning seeking), to entertain others, to explain oneself to someone, or to get closer to someone (intimacy). Participants were also given the option of specifying an alternative reason for telling the memory.

\section{Coding Meaning Making in Self-Defining Memory Narratives}

Three mutually exclusive meaning-related categories (no meaning, lesson learning, gaining insight) were coded as present or absent on the basis of the event, telling, and understanding narratives (McLean \& Thorne, 2001). ${ }^{2}$ Lesson learning was defined as reference to having learned a tangible and specific lesson from the memory that has implications for subsequent behavior in similar situations. Gaining insight was coded if the reporter inferred a meaning from the event that applied to larger areas of his or her life. Narratives coded as gaining insight typically referred to transformations of self or relationships.

The author coded all narratives for meaning and was blind to functions while coding. A coder, who was blind to the hypotheses, rated $30 \%$ of the memories for reliability, which was acceptable for meaning overall $(\kappa=$ $.83)$, no meaning $(\kappa=.86)$, lessons $(\kappa=.78)$, and insights $(\kappa=.84)$.

\footnotetext{
${ }^{1}$ Participants assigned to the other category either reported their ethnicity as other, reported a religion, or reported an ethnicity that did not fit into the listed categories.

${ }^{2}$ The manual for coding meaning can be obtained from Kate C. McLean.
} 


\section{Results}

\section{Overview of Analyses}

The goal was to compare across types of functions and because most participants reported three memories, ${ }^{3}$ some of which were told for both self-explanation and entertainment, two subsamples were created to preserve independence of data. The sample was split into participants who reported both self-explanation and entertainment memories $(n=37)$, the within sample, and participants who reported only entertainment $(n=40)$ or only selfexplanation memories $(n=67)$, the between sample. This strategy reduced the sample size, but it afforded statistical comparisons across functions for participants with independent and with dependent data. All data were aggregated and the percentages of each memory feature were computed per participant.

\section{Preliminary Statistics: Descriptives and Gender}

Table 1 shows descriptive statistics of the pertinent variables. Gender differences were examined on the main variables of interest. Results indicated that across all memories, males $(M=18.93$, $S D=1.29)$ were slightly older than females $(M=18.57, S D=$ $1.07), t(182)=2.02, p<.05$, though the difference was negligible. Males $(M=0.21, S D=0.25)$ were also more likely than females $(M=0.14, S D=0.20)$ to tell memories for entertainment, $t(183)=2.02, p<.05$. There were no gender differences in the frequency of telling, $t(179)=-1.58, n s$, or the number of people told, $t(181)=1.02, n s$, or for any of the other main variables.

In terms of audiences, using memories as the unit of analysis, friends $(38 \%)$ were the most common audience for adolescents, followed by parents-family (14\%), romantic partners $(7 \%)$, teachers-coaches $(5 \%)$, peers-family $(1 \%)$, strangers $(1 \%)$, and others (11\%); $23 \%$ of the memories did not include an audience in the report.

\section{Telling Functions}

Ninety percent $(n=492)$ of the memories had reportedly been told in the past, and $64 \%$ of the memories $(n=357)$ included a report of why the memory was told that fit into the categories listed above. Overall, self-explanation was the most commonly reported function $(27 \%)$, followed by entertainment (17\%), validation

Table 1

Means and Standard Deviations of Relevant Variables

\begin{tabular}{lrc}
\hline \multicolumn{1}{c}{ Variable } & $M$ & $S D$ \\
\hline Subject age & 18.75 & 1.19 \\
Age in memory & 13.33 & 3.09 \\
Age memory was told & 16.00 & 2.71 \\
Lessons (\%) & 0.10 & 0.18 \\
Insights (\%) & 0.21 & 0.26 \\
Total meaning (\%) & 0.31 & 0.31 \\
Functions (\%) & & \\
$\quad$ Self-explanation & 0.27 & 0.30 \\
Entertainment & 0.17 & 0.23 \\
Validation & 0.09 & 0.17 \\
Intimacy & 0.08 & 0.16 \\
$\quad$ Meaning seeking & 0.03 & \\
\hline
\end{tabular}

(10\%), intimacy (8\%), and meaning seeking (4\%). For those memories that did not fit into those categories, participants reported their own reason for telling, which included emotion regulation $(4 \%)$, to share experiences or part of one's life $(4 \%)$, the person was asked (2\%), for mutual reminiscence $(1 \%)$, and for generative reasons $(1 \%)$. Four percent of the memories contained a combination of functions, and $6 \%$ of the memories included no reason for telling. Unfortunately, sample sizes were quite small for the functions provided by the participants, so not all subsequent analyses included these functions, but future studies might include them as they may provide interesting insight into different telling contexts.

\section{Self-Explanation and Entertainment Functions}

Meaning. Memories told for self-explanation and for entertainment were examined in relation to reported meaning and audience. As expected, meaning was generally more common in memories told for self-explanation than entertainment. For the within sample, there was more total meaning (lessons plus insights $)$ in the memories told for self-explanation $(M=0.15, S D=$ $0.19)$ than memories told for entertainment $(M=0.06, S D=$ $0.13)$ : for total meaning paired, $t(36)=2.70, p<.05$. There was also a higher frequency of lessons in the self-explanation memories $(M=0.05, S D=0.12)$ than in the entertainment memories $(M=0.01, S D=0.05)$, paired $t(36)=1.96, p=.06$. For the between sample, more total meaning was found in the memories told for self-explanation $(M=0.35, S D=0.32)$ than those memories told for entertainment $(M=0.22, S D=0.27)$, meaning independent $t(105)=-2.05, p<.05$. More insights were also found in the memories told for self-explanation $(M=0.25, S D=$ $0.27)$ than for entertainment $(M=0.13, S D=0.21)$, independent $t(105)=-2.33, p<.05$.

Audience role. Unexpectedly, there were no significant differences for telling family, friends, or romantic partners (including when friends and romantic partners were included as one peer category) for functions in the between or within sample.

Several age variables were examined, including age in the memory, age the memory was told, and current participant age, in relation to audience role. As can be seen in Table 1, a wide range of adolescence was represented as the average age in the memories was 13 , and these memories were told at age 16 by participants who were age 19 at the time of the study. As expected, age that the memory was told was negatively related to telling family, $r(134)=$ $-.24, p<.01$, and positively related to telling friends, $r(134)=$ $.30, p<.001$, and to telling romantic partners, $r(134)=.19, p<$ .05 . Similarly, age in the memory was negatively related to telling family, $r(185)=-.16, p<.05$, and positively related to telling friends, $r(185)=.21, p<.01$. No associations were found between current age and audience. Using memories as the unit of analysis, results showed that both male adolescents (59\%) and female adolescents (58\%) were predominantly telling mixedgender groups their memories. For male adolescents, females were the audiences for $24 \%$ of memories and males for $17 \%$ of memories. For female adolescents, females were the audience for $33 \%$ of memories and males for $9 \%$ of memories.

\footnotetext{
${ }^{3}$ Three participants did not report all three memories, but with aggregated data by percentages their data were able to be included.
} 
To further explore the role of different audiences and when telling occurs, exploratory analyses were conducted to examine how long after the event the memory was told for audience and functions, using all of the functions reported. Memories that were told within 1 week of the event were more likely to be told to family, $r(185)=.19, p<.01$, and not to romantic partners, $r(185)=-.15, p<.05$, and were also likely to be told for emotion regulation, $r(185)=.25, p<.01$. Memories that were told more than a month after the event were more likely to be told to romantic partners, $r(185)=.20, p<.01$, and friends, $r(185)=$ $.26, p<.001$, and were more likely to be told to develop intimacy, $r(185)=.22, p<.01$. Further, the number of people to whom memories were told was positively associated with the age memories were told, $r(97)=.30, p<.01$, showing social network expansion or possibly that as one ages there are more opportunities to tell memories.

Finally, there were no differences for participant age or age in memory in relation to any of the functions or untold memories, or the report of insights, except that age in memory was positively associated with telling for the function of emotion regulation, $r(185)=.17, p<.05$. It is interesting that there was also an inverse relationship between current age and the report of lessons, $r(184)=-.18, p<.05$, suggesting that lesson learning is more of an early or midadolescent phenomenon.

Narrative content. Because these statistical data are drawn from a data set of rich narratives, a content analysis of the topics of memories told for self-explanation and entertainment was done to delineate what about the self was being communicated (see Table 2). Though statistical analyses were not done on these topics, a reliability analysis was done on the topics shown in Table 2. Acceptable levels of reliability were achieved on 25 cases (topics of self-explanation memories, $\kappa=.93$; topics of entertainment, $\kappa=1.00$ )

Memories told for self-explanation were most likely to comprise memories about relational gains (e.g., falling in love, feeling close to one's family) and losses (e.g., death, divorce, break-ups). Achievement memories (e.g., passing or failing a test, winning a game) were also common, as were memories about self-facts or timeline memories (e.g., one began home schooling in the 7th grade). The largest category of entertainment memories was mishaps. This category largely comprised physical accidents (e.g., car accidents, getting hit in the face with a ball) or stories of adventures and escapades that had the potential to or did go awry (e.g., snowboarding and almost getting hurt). Achievement was also

Table 2

Topics of Self-Explanation and Entertainment Memories

\begin{tabular}{cc}
\hline \multicolumn{1}{c}{ Topic } & $\%$ \\
\hline Self-explanation & \\
Relational loss & 36 \\
Relational gain & 30 \\
Fact-timeline (self) & 20 \\
Achievement & 14 \\
Entertainment & \\
Mishaps & 42 \\
Relationships & 27 \\
Achievement & 23 \\
Rebellion & 7 \\
\hline
\end{tabular}

present in entertainment memories, as was adolescent rebellion (e.g., getting drunk, high, or arrested) and relationship stories.

\section{Narrative Examples}

The results now turn to two specific narratives in order to contextualize the findings regarding telling functions.

Self-explanation. Ed was 18 at the time of the study and reported the following event, which occurred at age 16 or 17 and was told to 5-10 good friends. The insight reported is indicated in italics.

\section{Event narrative}

(age 16 or 17):

I was at my friend's house one night with my main group of friends. They were all smoking marijuana and drinking. I did not feel comfortable with trying marijuana. They tried hard to get me to try it, but I chose not to. One of my friends (my best) supported my choice. I learned who my real friends were. But more importantly, I learned that I can be strong with my decisions if I choose to, regardless of the outside influence.

Telling narrative (age 17 or 18):

Understanding narrative: The message is fairly obvious, but every time a situation similar to that one comes up, I can think back and tell myself that I can be firm with my decision, whatever that might be

Ed's narrative illustrates how meaning can be used to communicate important features of identity such as values. Ed also offers a good example of meaning making and how meaning is shared with others to maintain and to strengthen one's identity.

Entertainment. In contrast to Ed's narrative of meaning making and the growth of self-understanding, Bobby, age 18, reported a memory told for entertainment. Bobby was 16 at the time of the event, which was told to more than 10 people and was specifically told to his brother several weeks after the event occurred. There was no meaning reported in the following event, telling, and understanding narratives.

Event narrative

(age 16):
We had this one planned out for weeks before. It is not that we did not like the girls, but they were just our opposites, the female version of us. So we decided to use my house as a home base and proceeded at 1 a.m. to do as much damage as humanly possible to all six houses. Thiswas probably one of the more fun mo- 
ments of my life as we raced around the San Fernando Valley toilet papering their houses till they looked like white waterfalls. And the best part, the following Monday at school, five of the six girls ended up blaming the sixth one and her house got toilet papered the following week too. Truly a great couple of weeks.

Telling narrative (age 18):

He [brother] wanted to know what I was up to and of course he was in college so nothing I did was probably too important. So I decided to tell him about this little incident. Of course I overdramatized it and made it into some huge quest. He absolutely loved the story, from buying $\$ 100$ worth of toilet paper to speeding away from Western Security. And I love telling the story too, so I get just as much of a kick out of it.

Understanding narrative: I understand it pretty well. I played it over quite a bit in my mind.

Bobby's narrative contrasts to Ed's in that there appeared to be no effort toward reporting or understanding the greater meaning of this event. However, Bobby has chosen it as one of his selfdefining memories, suggesting that this adventure is an important part of his identity.

\section{Discussion}

This study is the first to take a narrative approach to studying self-defining memory-telling functions. In terms of functions, mirroring studies with other age groups (Pasupathi, Henry, \& Carstensen, 2002), telling for self-explanation was the most commonly reported function. Further, in mirroring a study with late adolescent's most recent memories but using different analytic strategies (Pasupathi, 2005), telling for self-explanation and entertainment showed different narrative patterns, the former of which were more likely to show explicit meaning than the latter. There were no differences for telling functions for parents and peers, but peers were increasingly likely to be the recipients of self-defining memory telling across adolescence, whereas parents were audiences at earlier ages. All of the results will now be addressed in turn.

Examining telling functions and meaning making is important because it affords a look at the personal as well as the social level of narrative identity. Meaning appears to be more relevant or appropriate when telling for self-explanation, which may allow one to develop, strengthen, and to confirm insights about the self. For example, the insight that Ed gained about his strength of character was enhanced by telling the memory as he confirmed his self-views with like-minded people, and other's acceptance in turn appeared to strengthen Ed's self-views, revealing a cyclical process of the self and social functions of memory telling (Nelson, 2003).

Relational concerns, mainly gains and losses, were the most common topic of memories told for self-explanation. Many of these memories were about being wronged by a friend or about when a friend did something supportive, providing an opportunity to communicate one's values and needs in relationships, which would be important to share in developing peer relationships. The distinction between relational gains and losses echoes a recent study on self-defining relationship memories in adolescence, which distinguished between separation and closeness as key concerns of such memories (McLean \& Thorne, 2003). The results of this study suggest that relationship memories are not only an important part of one's internal self-representation but are also crucial to telling the self to others.

It is interesting that although meaning overall was more common in memories told for self-explanation, lessons were more common at younger ages, suggesting a developmental component to the kinds of meanings that adolescents make. This finding is consistent with Pratt et al.'s (1999) cross-sectional work, which showed that meaning increased in complexity across the life span. The present finding suggests that lessons are a less sophisticated form of reasoning, which is consistent with the idea that lessons involve drawing more narrow conclusions about oneself and the world.

Although memories told for self-explanation appear to be an important part of identity construction due to the presence of explicit meaning, memories told for entertainment were also chosen as self-defining, suggesting that they too serve a purpose in identity development. The purpose of memories told for entertainment may be to allow connection with others without the work of communicating meaning or engaging in deeper kinds of personal disclosure that may be more risky (McLean \& Thorne, in press). Indeed, memories told for entertainment focused on episodes that have great potential to be entertaining stories-mishaps, in which something goes wrong and is resolved (Labov \& Waletzky, 1967). Perhaps telling mishap stories communicates some details of life experience in a light conversation so that the self comes across without the heavy demand on the teller and the listener that may come with more personal self-disclosure.

It is interesting that male adolescents were more likely than female adolescents to tell memories for entertainment. If selfexplanation is construed as a more intimate form of self-disclosure than entertainment, then these results follow research showing female adolescents' increasing proclivity for intimacy (Sharabany et al., 1981). On the other hand, these results might support research that has found that males and females reach similar levels of intimacy by late adolescence but construe or act out intimacy differently (Floyd, 1997; Rice \& Mulkeen, 1995). Telling memories for entertainment may marry two features of male intimacy, self-disclosure and shared adventures (Camarena et al., 1990), as males disclose about adventures.

In terms of audience, it was interesting that although parents and peers did not play different roles for telling functions, they did play different roles as audiences in terms of age. Indeed, it appears that age is the discriminatory factor in what and who to tell, rather than functions. Parents were audiences for adolescents at earlier ages and tended to be more immediate audiences than peers. Parents appeared to have a role in the immediate working out of experiences for adolescents, regulating the emotion of the events. On the other hand, peers were told memories that had already been well formed and were used to develop intimacy for both male and female adolescents. Although it was not possible to examine how individual stories are shared over time in this study, it is possible that parents help adolescents to form stories in early adolescence 
that are then transferred to peer audiences in later adolescence to develop new relationships. This interpretation suggests a developmental trend in relationships in which parents do not lose their importance, because those same stories that parents were involved in are shared with new audiences to develop a different kind of intimacy. Telling stories that have been shared previously with parents in new and developing peer relationships may be one way that the pattern of connectedness with parents is maintained (Grotevant \& Cooper, 1985).

Overall, the results of this study show that identity is made up of meaning-filled experiences and also of self-defining fun experiences that induce pleasure and enjoyment. These findings suggest that the framework in which the study was situated may be missing a piece of narrative identity as traditional research on narrative identity focuses on difficult and challenging events and the meanings made of those experiences (see McLean \& Thorne, in press; Thorne, 2004). Recently, a proposal was made that memories told for entertainment represent a different kind of meaning, meaning that centers on the valued audience for one's stories (McLean \& Thorne, in press). For example, Bobby's narrative of telling his brother about the toilet papering incident insinuated that the telling was intended to gain recognition of an identity that Bobby was trying to construct as well as to impress and to entertain his older brother. The memory was also at least 2 years old, suggesting that it was not simply a funny story he picked out of his hat but an enduring memory that helps him to define himself. It might even have developed into an enduring memory partly because of the positive response he received from his brother. Narratives like Bobby's suggest that bringing narrative identity into the social world may involve revising common notions of meaning to include the gains and losses to identity in sharing stories about the past. It is important to note that remembering the humorous, comedic, and adventurous parts of one's life may be just as important as recalling meaning-filled memories or memories that represent less entertaining aspects of the self.

\section{Limitations, Future Directions, and Conclusion}

It is important to address some limitations of this study and to suggest some ideas for future research. First, the present study was retrospective. Studying how conversational turns and ongoing experiences in memory telling affect memory construction is crucial to elaborating the process by which memories and identity are socially constructed. Second, this study forced a choice between memory functions, which may not be exclusive (McLean \& Thorne, in press). Third, there was no specification of what kind of telling narrative to share; participants were asked to simply pick a memorable time in which the memory was shared. Future research should consider specifying different telling scenarios to examine how such scenarios might be different such as asking for times in which parents or peers were told. Fourth, though there was a broad age range in this study, the average age was 19 and all participants were college students. Telling functions may differ in older age groups or in groups that are not in a college setting. For example, intimacy might be a more important function in a young to midadult sample in which people are developing long-term romantic relationships (Alea \& Bluck, 2003; Webster, 2003). Future research should consider longitudinal designs where development can be examined within persons.
An important limitation that deserves discussion is culture. Although this study was unable to address cultural differences, there are some important implications from this study for cultural work on identity and memory telling. First, it is important to note that the idea of personal identity is a culturally based phenomenon (e.g., Markus \& Kitayama, 1991) because identity is developed through repeated social interactions and participation in culturally relevant activities, which can differ markedly (e.g., Bruner, 1990; Miller, Mintz, Hoogstra, Fung, \& Potts, 1992; Rogoff, 1990). Though the American sample examined here fits in with the notion of an independent, autonomous identity as the desired developmental outcome, other cultures may desire more interdependent and/or context-dependent identities (e.g., Wang, 2004). Memory telling is a useful way to examine cultural differences in identity development as values about what should be remembered can be communicated in memory-telling interactions (e.g., Pasupathi et al., 2002). These differences are crucial to understanding not only how other groups construe identity but also to compare other concepts of identity with the more dominant conceptions of identity to see what can be learned through understanding different ways of thinking about and valuing identity.

In conclusion, the interface between personal and social worlds has become more and more apparent in the burgeoning field of memory telling (see Pasupathi, 2001; Thorne, 2000, 2004). Examining both the person-level individual differences in the construction of a narrative identity as well as locating the abstract entity of identity in lived experience moves the field toward a more concrete and rich understanding of how identity is constructed and communicated. Identity is represented by great variations in experiences and narrative constructions such as deep reflections into one's personhood as well as adventurous and joyous stories. Investigating the landscape of autobiographical memory and identity necessitates considering how many kinds of memories are used as people define themselves to and with others.

\section{References}

Alea, N., \& Bluck, S. (2003). Why are you telling me that? A conceptual model of the social function of autobiographical memory. Memory, 11, 165-178.

Azmitia, M. (2002). Self, self-esteem, conflicts, and best friendships in early adolescence. In T. M. Brinthaupt \& R. P. Lipka (Eds.), Understanding the self of the early adolescent (pp. 167-192). Albany, NY: State University of New York Press.

Blagov, P. S., \& Singer, J. A. (2004). Four dimensions of self-defining memories (specificity, meaning, content, and affect) and their relationships to self-restraint, distress, and repressive defensiveness. Journal of Personality, 72, 481-512.

Bruner, J. S. (1990). Acts of meaning. Cambridge, MA: Harvard University Press.

Camarena, P. M., Sarigiana, P. A., Petersen, A. C. (1990). Gender-specific pathways to intimacy in early adolescence. Journal of Youth and Adolescence, 19, 19-32.

Carstensen, L. L. (1995). Evidence for a life-span theory of socioemotional selectivity. Current Directions in Psychological Science, 4, 151-156.

Charles, S. T., \& Pasupathi, M. (2003). Age-related patterns of variability in self-descriptions: Implications for everyday affective experience. Psychology and Aging, 18, 524-536.

Erikson, E. H. (1968). Identity: Youth and crisis. New York: Norton.

Floyd, K. (1997). Brotherly love: II. A developmental perspective on liking, love, and closeness in the fraternal dyad. Journal of Family Psychology, 11, 196-209. 
Furman, W. (1989). The development of children's social networks. In D. Belle (Ed.), Children's social networks and social supports (pp. 151172). Oxford, England: Wiley.

Grotevant, H. D. (1993). The integrative nature of identity: Bringing the soloists to sing in the choir. In J. Kroger (Ed.), Discussions on ego identity (pp. 121-146). Hillsdale, NJ: Erlbaum.

Grotevant, H. D., \& Cooper, C. R. (1985). Patterns of interaction in family relationships and the development of identity exploration in adolescence. Child Development, 56, 415-428.

Habermas, T., \& Bluck, S. (2000). Getting a life: The emergence of the life story in adolescence. Psychological Bulletin, 126, 248-269.

Harter, S. (1999). The development of self representations. In W. Damon \& N. Eisenberg (Eds.), Handbook of child psychology: Social, emotional, and personality development (pp. 553-618). New York: Wiley.

Hunter, F. T., \& Youniss, J. (1982). Changes in functions of three relations during adolescence. Developmental Psychology, 18, 806-811.

King, L. A. (2001). The hard road to the good life: The happy, mature person. Journal of Humanistic Psychology, 41, 51-72.

Kroger, J. (2000). Identity development: Adolescence through adulthood. Thousand Oaks, CA: Sage.

Labov, W., \& Waletzky, J. (1967). Narrative analysis. In J. Helm (Ed.), Essays on the verbal and visual arts (pp. 12-44). Seattle: University of Washington Press.

Larson, R. W., \& Richards, M. H. (1991). Boredom in the middle school years: Blaming schools versus blaming students. American Journal of Education, 99, 418-443.

Markus, H., \& Kitayama, S. (1991). Culture and the self: Implications for cognition, emotion, and motivation. Psychological Review, 98, 224253.

McAdams, D. P. (1993). The stories we live by: Personal myths and the making of the self. New York: Morrow.

McAdams, D. P. (2001). The psychology of life stories. Review of General Psychology, 5, 100-122.

McCabe, A., Capron, E., \& Peterson, C. (1991). The voice of experience: The recall of early childhood and adolescent memories by young adults. In A. McCabe \& C. Peterson (Eds.), Developing narrative structure (pp. 137-174). Hillsdale, NJ: Erlbaum.

McLean, K. C., \& Thorne, A. (2001). Manual for coding meaning-making in self-defining memories. Unpublished manuscript, University of California, Santa Cruz.

McLean, K. C., \& Thorne, A. (2003). Adolescents's self-defining memories about relationships. Developmental Psychology, 39, 635-645.

McLean, K. C., \& Thorne, A. (in press). Identity light: Entertainment as a vehicle for self-development. In D. P. McAdams, R. Josselson, \& A. Lieblich (Eds.), Narrative study of lives, self, and identity. Washington, DC: American Psychological Association.

Miller, P. J., Mintz, J., Hoosgstra, L., Fung, H., \& Potts, R. (1992). The narrated self: Young children's construction of self in relation to others in conversational stories of personal experience. Merrill-Palmer Quarterly, 38, 45-67.

Morling, B., \& Epstein, S. (1997). Compromises produced by the dialectic between self-versification and self-enhancement. Journal of Personality and Social Psychology, 73, 1268-1283.

Nelson, K. (2003). Self and social functions: Individual autobiographical memory and collective narrative. Memory, 11, 125-136.

Pals, J. L. (2005). Transforming the self: A two-dimensional process model of identity construction within narratives of difficult life events. Manuscript submitted for publication.

Pasupathi, M. (2001). The social construction of the personal past and its implications for adult development. Psychological Bulletin, 127, 651672.

Pasupathi, M. (2005). Told and never told tales: Written narratives about personal experiences are affected by prior disclosure. Manuscript submitted for publication.
Pasupathi, M. (in press). Silk from sows' ears: Collaborative construction of everyday selves in everyday stories. In D. P. McAdams, R. Josselson, \& A. Lieblich (Eds.), Narrative study of lives, self, and identity. Washington, DC: American Psychological Association.

Pasupathi, M., Henry, R. M., \& Carstensen, L. L. (2002). Age and ethnicity differences in storytelling to young children: Emotionality, relationality, and socialization. Psychology and Aging, 17, 610-621.

Pasupathi, M., Lucas, S., \& Coombs, A. (2002). Conversational functions of autobiographical remembering: Long-married couples talk about conflicts and pleasant topics. Discourse Processes, 34, 163-192.

Pennebaker, J. W., \& Francis, M. E. (1999). Linguistic inquiry and word count. Mahwah, NJ: Erlbaum.

Piaget, J. (1965). The moral judgment of the child. New York: Free Press.

Pillemer, D. B. (1992). Remembering personal circumstances: A functional analysis. In E. Winograd \& U. Neisser (Eds.), Affect and accuracy in recall: Studies of "flashbulb" memories. Emory Symposia in Cognition (Vol. 4, pp. 236-264). New York: Cambridge University Press.

Pratt, M., Norris, J. E., Arnold, M. L., \& Filyer, R. (1999). Generativity and moral development as predictors of value-socialization narratives for young persons across the adult life span: From lessons learned to stories shared. Psychology and Aging, 14, 414-426.

Reis, H. T., Lin, Y., Bennett, E. M., \& Nezlek, J. B. (1993). Change and consistency in social participation during early adulthood. Developmental Psychology, 29, 633-645.

Rice, K. G., \& Mulkeen, P. (1995). Relationships with parents and peers: A longitudinal study of adolescent intimacy. Journal of Adolescent Research, 10, 338-357.

Rimé, B., Mesquita, B., Philippot, P., \& Boca, S. (1991). Beyond the emotional event: Six studies on the social sharing of emotion. Cognition \& Emotion, 5, 435-465.

Rogoff, B. (1990). Apprenticeship in thinking: Cognitive development in social context. London: Oxford University Press.

Sanitioso, R., Kunda, Z., \& Fong, G. T. (1990). Motivated recruitment of autobiographical memories. Journal of Personality and Social Psychology, 59, 229-241.

Sharabany, R., Gershoni, R., \& Hofman, J. E. (1981). Girlfriend, boyfriend: Age and sex differences in intimate friendship. Developmental Psychology, 17, 800-808.

Shaver, P., Furman, W., \& Buhrmester, D. (1985). Transition to college: Network changes, social skills, and loneliness. In S. Duck \& D. Perlman (Eds.), Understanding personal relationships: An interdisciplinary approach (pp. 193-219). London: Sage.

Singer, J. A., \& Moffitt, K. H. (1991-1992). An experimental investigation of specificity and generality in memory narratives. Imagination, Cognition, and Personality, 11, 233-257.

Sullivan, H. S. (1953). The interpersonal theory of psychiatry. New York: Norton.

Surra, C. A., \& Bohman, T. (1991). The development of close relationships: A cognitive perspective. In G. J. O. Fletcher \& F. D. Fincham (Eds.), Cognition in close relationships (pp. 281-305). Hillsdale, NJ: Erlbaum.

Thorne, A. (2000). Personal memory telling and personality development. Personality \& Social Psychology Review, 4, 45-56.

Thorne, A. (2004). Putting the person into social identity. Human Development, 47, 361-365.

Thorne, A., \& McLean, K. C. (2002). Gendered reminiscence practices and self-definition in late adolescence. Sex Roles: A Journal of Research, 46, 261-271.

Thorne, A., \& McLean, K. C. (2003). Telling traumatic events in adolescence: A study of master narrative positioning. In R. Fivush \& C. Haden (Eds.), Connecting culture and memory: The development of an autobiographical self (pp. 169-185). Mahwah, NJ: Erlbaum.

Thorne, A., McLean, K. C., \& Lawrence, A. (2004). When remembering is 
not enough: Reflecting on self-defining events in late adolescence. Journal of Personality, 72, 513-542.

Tversky, B., \& Marsh, E. J. (2000). Biased retellings of events yield biased memories. Cognitive Psychology, 40, 1-38.

Wang, Q. (2004). The emergence of cultural self-constructs: Autobiographical memory and self-description in European and American and Chinese children. Developmental Psychology, 40, 3-15.

Webster, J. D. (2003). The reminiscence circumplex and autobiographical memory functions. Memory, 11, 203-215.
Youniss, J., \& Smollar, J. (1985). Adolescent relations with mothers, fathers, and friends. Chicago: University of Chicago Press.

Received July 23, 2004

Revision received December 15, 2004

Accepted March 4, 2005

\section{Members of Underrepresented Groups: Reviewers for Journal Manuscripts Wanted}

If you are interested in reviewing manuscripts for APA journals, the APA Publications and Communications Board would like to invite your participation. Manuscript reviewers are vital to the publications process. As a reviewer, you would gain valuable experience in publishing. The $\mathrm{P} \& \mathrm{C}$ Board is particularly interested in encouraging members of underrepresented groups to participate more in this process.

If you are interested in reviewing manuscripts, please write to Demarie Jackson at the address below. Please note the following important points:

- To be selected as a reviewer, you must have published articles in peer-reviewed journals. The experience of publishing provides a reviewer with the basis for preparing a thorough, objective review.

- To be selected, it is critical to be a regular reader of the five to six empirical journals that are most central to the area or journal for which you would like to review. Current knowledge of recently published research provides a reviewer with the knowledge base to evaluate a new submission within the context of existing research.

- To select the appropriate reviewers for each manuscript, the editor needs detailed information. Please include with your letter your vita. In your letter, please identify which APA journal(s) you are interested in, and describe your area of expertise. Be as specific as possible. For example, "social psychology" is not sufficient-you would need to specify "social cognition" or "attitude change" as well.

- Reviewing a manuscript takes time (1-4 hours per manuscript reviewed). If you are selected to review a manuscript, be prepared to invest the necessary time to evaluate the manuscript thoroughly.

Write to Demarie Jackson, Journals Office, American Psychological Association, 750 First Street, NE, Washington, DC 20002-4242. 